\title{
BIOTRANSFORMAÇÃO DO LIMONENO
}

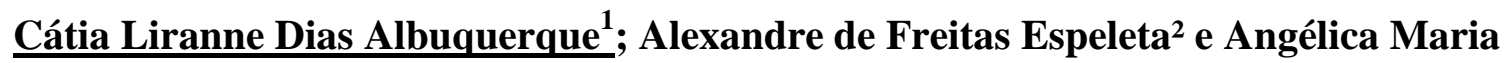 \\ Lucchese $^{3}$ \\ 1. Bolsista PIBIC/CNPq, Graduanda em Ciências Biológica, Universidade Estadual de Feira de Santana, e-mail: \\ catialirannealbuquerque@hotmail.com \\ 2. Orientador, Departamento de Ciências Exatas, Universidade Estadual de Feira de Santana, e-mail: \\ espeleta8@gmail.com \\ 3. Co-orientadora, Departamento de Ciências Exatas, Universidade Estadual de Feira de Santana, e-mail: \\ angélica.lucchese@gmail.com
}

PALAVRAS-CHAVE: Biocatálise; $\alpha$-terpineol; compostos aromáticos.

\section{INTRODUÇÃO}

De acordo com a resolução de No. 22 de 1977 da CNNPA (Comissão Nacional de Normas e Padrões para Alimentos), aromatizante "é a substância ou mistura de substâncias possuidoras de propriedades odoríferas ou sápidas, capaz de conferir ou intensificar o aroma dos alimentos, inclusive as bebidas". Substâncias aromatizantes estão presentes em diversos produtos, desde cosméticos até alimentos e podem ser obtidos química ou naturalmente. Porém, devido a uma crescente exigência dos consumidores, há uma maior necessidade de obter compostos aromáticos por vias naturais, de origem biológica (Janssens et al. 1992; Berger, 1995). Uma dessas possibilidades é o uso de micro-organismos através da biotransformação (Medeiros, 2006).

O uso de micro-organismos para obtenção de diversos compostos já é conhecido em vários setores da indústria (Canhos, 2003) e os fungos se demonstraram os micro-organismos mais eficientes na produção de compostos de aromas, e são inúmeros os estudos com diferentes espécies que apontam isso (Asakawa et al. 1991; Bushman \& Berger, 1994; Van Rensburg et. al 1997). Em meios de cultura ideais, os fungos convertem os substratos em compostos de aroma de forma mais eficiente quando comparadas a outros processos, nos quais as etapas de conversão podem ser múltiplas (Kempler, 1983).

Substratos como os terpenos são abundantes na natureza e são muito utilizados na indústria como aroma e fragrâncias (Schrader \& Berger, 2001). Os terpenos e seus derivados são os principais componentes responsáveis pelo odor característico dos óleos essenciais. $\mathrm{O}$ limoneno é um monoterpeno que está presente em frutas cítricas. O limoneno é um resíduo industrial da fabricação de suco de laranja amplamente produzido (Rezzadori \& Beneditti, 2009) que é precursor de diversas substâncias com potencial econômico (Tan, Day \& Cadwallader, 1998). Tendo em vista o potencial industrial/econômico do limoneno, este trabalho tem como alvo investigar o uso de limoneno na obtenção de derivados oxigenados de maior valor comercial, principalmente o $\alpha$-terpineol, a partir do uso de potenciais microorganismos biocatalisadores.

\section{MATERIAL E MÉTODOS}

Foi utilizado, como substrato, $R$-limoneno de procedência Sigma-Aldrich. Os fungos avaliados foram o Periconia byssoides (82/06), Periconia hispidula (42/07), Beltrania copaifera (80/07), Beltrania rhombica (35/06), Beltraniella portoricensis (17/11) e Beltraniella botryospora (375/12), que estão preservados no laboratório pelo método de Castellani (água estéril a temperatura ambiente) e foram cedidos pelo Laboratório de Micologia da UEFS. Os fungos foram reativados em placas contendo meio ágar batatadextrose (BDA) e postos numa estufa incubadora de Demanda Bioquímica de Oxigênio (BOD), na temperatura de $30^{\circ} \mathrm{C}$ durante oito dias para que houvesse crescimento de hifas. Após esse período, cinco discos de $5 \mathrm{~mm}$ de diâmetro de cada fungo foram transferidos para frascos reagentes $(250 \mathrm{~mL})$, contendo $100 \mathrm{~mL}$ do meio caldo batata-dextrose (BD), que foram 
postos em uma câmara incubadora com agitação orbital, a $29{ }^{\circ} \mathrm{C}$ e sob $150 \mathrm{rpm}$, durante $96 \mathrm{~h}$, para crescimento de micélio. Após esse tempo, $50 \mu \mathrm{L}$ de limoneno $95 \%$ foram adicionados em cada frasco, exceto nos controles. $\mathrm{O}$ experimento foi feito em triplicata +01 controle para cada fungo. No controle, apenas o limoneno não foi adicionado, dessa forma, os compostos gerados pela inserção do limoneno no meio puderam ser diferenciados. A coleta foi feita $24 \mathrm{~h}$ após a adição do limoneno e, foram transferidos $5 \mathrm{~mL}$ de cada frasco reagente para fracos de amostra $(15 \mathrm{~mL})$. Após isso, para realização de extração parcial, foram adicionados $5 \mathrm{~mL}$ de acetato de etila à parcela transferida. A mistura foi agitada por 5 minutos e, após repouso de outros 15 minutos, a fração sobrenadante foi extraída com auxílio de uma pipeta Pasteur. Após extração do meio líquido com acetato de etila, foi feita a identificação dos produtos formados utilizando um cromatógrafo a gás acoplado ao espectrômetro de massas (GC-MS), modelo GCMS-QP2010. A temperatura inicial foi de $60{ }^{\circ} \mathrm{C}$, com elevação de $6{ }^{\circ} \mathrm{C} /$ minuto até alcançar os $220^{\circ} \mathrm{C}$. Foram injetados $0,2 \mu \mathrm{L}$ de cada amostra no CG-MS. A identificação dos constituintes foi realizada pelo seu espectro de massas, por comparação com a biblioteca do equipamento, fontes da literatura (Adams, 2007) e injeções de padrões. A quantificação do percentual relativo dos constituintes identificados foi calculada com base nas áreas dos picos cromatográficos correspondentes (método da normalização) em cromatógrafo a gás com detector de ionização de chama.

Os biocatalisadores selecionados na etapa anterior foram submetidos ao processo de otimização. Os fungos que converteram o limoneno no produto de maior interesse, que no caso é o $\alpha$-terpineol, foram cultivados em dois tratamentos diferentes: (1) um contendo meio BDA puro e (2) o outro meio contendo BDA com 0,1\% de Limoneno. Neste último, foram adicionados, ao volume do meio BDA que seria utilizado, $0,1 \%$ de limoneno (i.e. para cada $250 \mathrm{~mL}$ de meio BDA foram acrescentados $250 \mu \mathrm{L}$ de limoneno). Após o desenvolvimento de hifas, cinco discos de $5 \mathrm{~mm}$ de diâmetro de cada fungo foram transferidos para frascos reagentes $(250 \mathrm{~mL})$ contendo $100 \mathrm{~mL}$ do meio caldo batata-dextrose (BD). Estes frascos reagentes foram postos em uma câmara incubadora com agitação orbital, a $29{ }^{\circ} \mathrm{C}$ e sob 150 rpm, durante $96 \mathrm{~h}$, para crescimento de micélio. Após o tempo, $50 \mu \mathrm{L}$ de limoneno $95 \%$ foram adicionados em cada frasco, exceto nos controles. $\mathrm{O}$ experimento foi feito em triplicata + 01 controle para cada fungo. Foram realizadas coletas com $6 \mathrm{~h}$ e $24 \mathrm{~h}$ após a adição do limoneno. A coleta, extração e análises cromatográficas foram realizadas da mesma forma como foi citado anteriormente.

Para construção da curva de calibração, é necessária a obtenção de $\alpha$-terpineol puro. Ele foi obtido seguindo a metodologia de Baptistella et. al (2008). Em um balão de duas bocas de $100 \mathrm{~mL}$, conectado a um funil de adição e a uma rolha esmerilhada, foram colocados o (+)-limoneno $(2,0 \mathrm{~g})$ e o diclorometano $(10 \mathrm{~mL})$. À parte, foi preparada uma solução de ácido tricloroacético $(2,9 \mathrm{~g}, 17,7 \mathrm{mmol}, 1,2 \mathrm{eq})$ em diclorometano $(5 \mathrm{~mL})$, que foi transferida para o funil de adição com a ajuda de um funil de haste longa. $O$ funil de adição foi fechado com tubo secante contendo cloreto de cálcio, iniciando-se a seguir um gotejamento lento (cerca de $30 \mathrm{~min}$ ) da solução ácida sobre a solução do limoneno, mantida à temperatura ambiente e sob agitação magnética constante. Após a adição, a mistura foi agitada por um tempo adicional de 30 min. Então, a solução de reação foi transferida para um funil de separação, extraindo-a com solução aquosa de bicarbonato de sódio $5 \%$ ( 2 x $10 \mathrm{~mL}$ ) e, em seguida, lavando-a com solução aquosa de cloreto de sódio $(1 \times 10 \mathrm{~mL})$. A fase orgânica foi seca sobre sulfato de sódio anidro, filtrando-a e removendo o solvente em um evaporador rotativo. O material bruto foi colhido para a próxima etapa. Em um balão de duas bocas de $100 \mathrm{~mL}$, conectado a um funil de adição e a uma rolha esmerilhada, o tricloroacetato de terpineol bruto obtido na etapa anterior foi dissolvido em metanol $(10 \mathrm{~mL})$. À parte, uma solução aquosa de $\mathrm{NaOH} 4,5 \mathrm{~mol} / \mathrm{L}(10 \mathrm{~mL})$ foi transferida para o funil de adição e foi adicionado, sob agitação constante à temperatura ambiente, gota à gota da solução metanólica. 
Após a adição (cerca de 30 min), a agitação magnética foi mantida por 30 minutos adicionais, com acompanhamento da reação por CCD (hexano:acetato de etila 20\%). Foi adicionado, então, uma solução aquosa de $\mathrm{HCl} 20 \%$ (v/v) gota a gota, até atingir pH 8-9, e após alguns minutos, por pressão reduzida, a mistura de reação foi evaporada. Foi extraído o resíduo com $30 \mathrm{~mL}$ de uma solução de hexano:acetato de etila $20 \%$ e, em seguida, a fase líquida foi transferida para um erlenmeyer e foi seca sobre sulfato de sódio anidro. Após a filtração e transferência para um balão tarado, um evaporador rotativo foi utilizado para evaporar o solvente. O terpineol bruto foi então purificado em coluna cromatográfica de sílica gel (1:60). A primeira coleta foi feita utilizando $150 \mathrm{~mL}$ de hexano, mudando em seguida para a solução hexano:acetato de etila 5\%, e fazendo coletas do gotejamento com o auxílio frascos $15 \mathrm{~mL}$, separando assim o terpeno de interesse.

\section{RESULTADOS E DISCUSSÃO}

Durante a reativação dos fungos, a cepa $17 / 11$ do fungo Beltraniella portoricensis não cresceu em placa. Tentou-se a reativação do fungo nos meios YM (yeast mold and broth), CMA (cenoura) e no AA (ágar-água), mas ele não cresceu em nenhum desses outros três meios. Na triagem inicial da atividade catalítica os fungos $B$. botryospora e $B$. rhombica converteram limoneno apenas em $\alpha$-terpineol. Já $B$. copaifera produziu, além do $\alpha$-terpineol, o limoneno-1,2-epóxido. Essa última substância também foi produzida pelo $P$. byssoides. No fungo $P$. hispidula, não houve conversão do substrato. Como esse trabalho visa o $\alpha$-terpineol como o produto de maior interesse, os três fungos (B. rhombica, B. copaifera e $B$. botryospora) que biotransformaram o limoneno em $\alpha$-terpineol passaram pelo experimento de otimização, em dois meios (BDA e BDA-limoneno). O resultado obtido através das análises cromatográficas mostraram diferenças temporais na conversão do substrato (tabelas 1 e 2).

Tabela 1. Médias e desvio padrão (DP) da porcentagem de conversão dos produtos encontrados na extração dos fungos cultivados no meio BDA. Letras iguais representam médias que se sobrepõe.

\begin{tabular}{cccccc}
\hline \multirow{2}{*}{ Fungos } & Produto obtido & \multicolumn{2}{c}{ Tempo 6h } & \multicolumn{2}{c}{ Tempo 24h } \\
\cline { 3 - 6 } & & $\begin{array}{c}\text { Média } \\
(\%)\end{array}$ & $\begin{array}{c}\text { DP } \\
(\%)\end{array}$ & $\begin{array}{c}\text { Média } \\
(\%)\end{array}$ & $\begin{array}{c}\text { DP } \\
(\%)\end{array}$ \\
\hline B. rhombica & $\boldsymbol{\alpha}$-Terpineol & $36^{\mathrm{a}}$ & 7,4 & $100^{\mathrm{d}}$ & 0 \\
B. botryospora & $\boldsymbol{\alpha}$-Terpineol & $0^{*}$ & 0 & $100^{\mathrm{d}}$ & 0 \\
B. copaifera & $\boldsymbol{\alpha}$-Terpineol & $0^{*}$ & 0 & $47,4^{\mathrm{b}}$ & 18,5 \\
& Limoneno-1,2-epóxido & $0^{*}$ & 0 & $31,4^{\mathrm{a}}$ & 16,3 \\
\hline *Não houve conversão de produtos. & & &
\end{tabular}

Tabela 2. Médias e desvio padrão (DP) da porcentagem de conversão dos produtos encontrados na extração dos fungos cultivados no meio BDA+limoneno. Letras iguais representam médias que se sobrepõe.

\begin{tabular}{cccccc}
\hline \multirow{2}{*}{ Fungos } & \multirow{2}{*}{ Produto obtido } & \multicolumn{2}{c}{ Tempo 6h } & \multicolumn{2}{c}{ Tempo 24 h } \\
\cline { 3 - 6 } & & $\begin{array}{c}\text { Média } \\
(\boldsymbol{\%})\end{array}$ & $\begin{array}{c}\text { DP } \\
(\boldsymbol{\%})\end{array}$ & $\begin{array}{c}\text { Média } \\
(\boldsymbol{\%})\end{array}$ & $\begin{array}{c}\text { DP } \\
(\boldsymbol{\%})\end{array}$ \\
\hline B. rhombica & $\boldsymbol{\alpha}$-Terpineol & $21,5^{\text {ab }}$ & 17,5 & $93,3^{\mathrm{cd}}$ & 11,7 \\
B. botryospora & $\boldsymbol{\alpha}$-Terpineol & $0^{*}$ & 0 & $96,7^{\mathrm{d}}$ & 5,7 \\
B. copaifera & $\boldsymbol{\alpha}$-Terpineol & $0^{*}$ & 0 & $78,2^{\mathrm{c}}$ & 8 \\
& Limoneno-1,2-epóxido & $0^{*}$ & 0 & $10,4^{\mathrm{b}}$ & 3,8 \\
\hline
\end{tabular}

*Não houve conversão de produtos.

O fungo B. rhombica (35/06), por exemplo, foi o único que demonstrou uma taxa de conversão do limoneno em $\alpha$-terpineol já nas extrações feitas seis horas após adição do 
substrato. Quando cultivados em meios diferentes, apenas o fungo B. copaifera mostrou diferença, convertendo mais limoneno em $\alpha$-terpineol quando cultivado no meio BDA com $0,1 \%$ limoneno. Para os outros fungos, não houve diferença na conversão de limoneno em $\alpha$ terpineol quando meios diferentes foram usados. Após ter conhecimento dos fungos que são mais eficientes na conversão do limoneno em um produto de interesse (no caso, o $\alpha$ terpineol), o próximo passo foi sintetizar o $\alpha$-terpineol quimicamente, obtido com $21 \%$ de rendimento, com pureza cromatográfica superior a 99\%. Com o $\alpha$-terpineol purificado, a curva de calibração poderá ser construída para determinação dos rendimentos cromatográficos durante as etapas posteriores de otimização.

\section{CONSIDERAÇÕES FINAIS}

Concluiu-se, a partir desse trabalho, que o fungo $P$. hispidula não é biotransformador do limoneno. Três dos seis fungos iniciais converteram limoneno no produto de maior interesse - o $\alpha$-terpineol. Sendo assim, dar continuidade a esse trabalho é vital, para determinação do rendimento cromatográfico de $\alpha$-terpineol, a partir do limoneno, e também para estabelecer o melhor tempo para coleta e extração total dos compostos, de forma que todo o substrato de limoneno seja convertido, mas que o produto - $\alpha$-terpineol - não seja metabolizado pelo fungo, maximizando sua produção.

\section{REFERÊNCIAS}

ADAMS, R. P. 2007: Identification of Essential Oil Components by Gas Chromatography/Mass Spectrometry. 4 ed. Allured Publishing Corporation, Illinois-USA.

ASAKAWA, Y., TAKAHASHI, H., TOYOTA, M. \& NOMA, Y. 1991: Biotransformation of monoterpenoids, (-)-and (+)-menthols, terpinlene and carvotanacetone by Aspergillus species. Phytochemistry 30, 3981-3987.

BAPTISTELlA, L.H.B., INAMURA, P.M., DE MELO, L.V. \& CASTELLO, C. 2008: Preparação do (+)- $\alpha$-terpineol a partir do (+)-limoneno: monoterpenos de odor agradável em um projeto para química orgânica experimental. Química Nova 32, 1069-1071.

BERGER, R. G. 1995: Aroma biotechnology. Springer, Berlin.

BUSHMANN, D. \& BERGER, R.G. 1994: Conversion of mircene by submerged cultured basiodiomycetes. Journal of Biotechnology 27, 39-43.

CANHOS, V.P. \& MANFIO, G.P. Recursos microbiológicos para biotecnologia. Homepage: https://www.faecpr.edu.br/site/documentos/recursos_microbiologicos_biotecnologia.pdf.

JANSSENS, L., DE POOTHER, H. L., SCHAMP, N. M., VANDAMME, E. J. 1992: Production of flavours by microorganisms. Process in Biochemistry 27, 195-215.

KEMPLER, G. M. 1983: Production of flavor compounds by microorganisms. Advances in Applied Microbiology 29, 29-51.

MEDEIROS, A. B. P.2006: Produção e Recuperação de aromas obtidos biotecnologicamente. Universidade Federal do Paraná, Curitiba.

REZZADORI, K. \& BENEDITTI, S. 2009: Proposições para valorização de resíduos do processamento do suco de laranja. Homepage: http://www.advancesincleanerproduction.net/second/files/sessoes/6a/4/K.\%20Rezzadori\%20\%20Resumo\%20Exp\%20-\%206A-4.pdf.

SCHRADER, J. \& BERGER, R. G. 2001: Biotechnological production of terpenoid flavor and fragrance compounds. In: REHM, H.-J., REED, G. (2nd Ed), Biotechnology. Weinheim: Wiley-VHC, 373-422.

TAN, Q., DAY, D. F., CADWALLADER, K. R. 1998: Bioconversion of (R)-(+)-limonene by P. digitatum (NRRL 1202). Process Biochemistry 33, 29-31.

VAN RENSBURG, E., MOLELEKI, N., VAN DER WALT, J. P., BOTES, P. J. \& VAN 